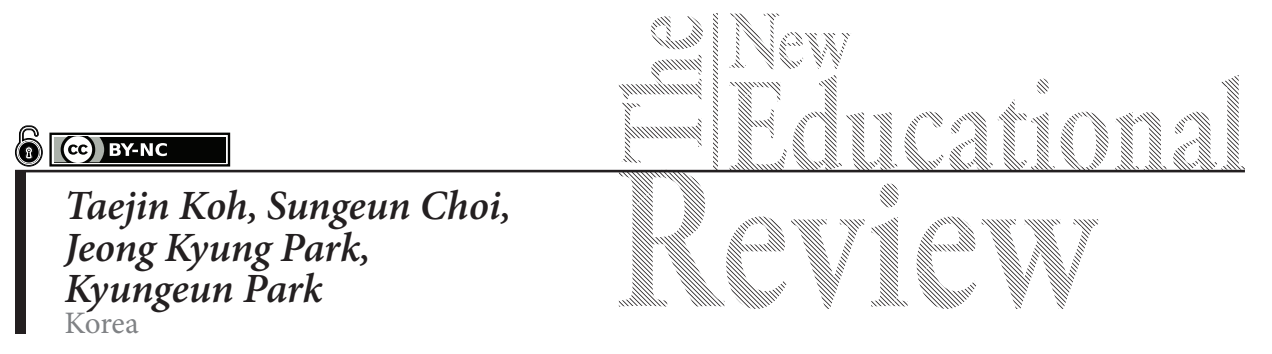

\title{
Are Tandem Classrooms Effective in Developing Intercultural Communicative Competence?
}

DOI: 10.15804/tner.2020.61.3.07

\begin{abstract}
The aim of this paper is to explore the effectiveness of tandem classrooms in promoting intercultural communicative competence by comparing the competence of students before and after participation in tandem classes. This research is based on the descriptive statistics from a survey administered at a university in South Korea. The survey was conducted in 2016 during the second semester, and it used students who participated in tandem classrooms by employing a questionnaire to measure the effectiveness of the tandem classrooms in relation to intercultural communicative competence and the students' perception of their own competence after completing the tandem classes. The result of the research shows that unlike the initial expectations, there is no meaningful sign that the surveyed students have developed intercultural communicative competence, which means that tandem classrooms did not actively help students improve this competence. In this study, an in-depth interview with students was also conducted in 2019 to find out why such a result occurred. Although tandem classrooms would be highly valuable as a language learning method, the approach may require redesigning and reimplementation in great detail to become a method for developing intercultural communicative competence. Therefore, this study highlights the underlying need for a revised curriculum for students attending tandem classrooms.
\end{abstract}

Key words: Tandem, Intercultural Communicative Competence, International Students, Tandem Classroom, Curriculum. 


\section{Introduction}

The tandem learning method is based on a mutual language exchange between the tandem partners. The term tandem was initially adopted to use for language education between French and German students in 1968 (Rosanelli, 1992). It is generally agreed that the tandem network, which was launched and developed by Jürgen Wolff, Marisa Delgado, Bernhard Leute, and Gracia Martín Torres in 1983 (Calvert, 1992), has been facilitated as a programme for foreign language learning (Rosanelli, 1992; Brammerts, 2001). The two main pillars of tandem learning are the principles of autonomy and reciprocity, i.e., the ability to take charge of and to be responsible for one's own learning and the goodwill of tandem partners to exchange knowledge and to support each other in the learning process, respectively (Brammerts 2001, pp. 10-15; Tardieu \& Horgues, 2020: pp. 2-3).

Tandem learning not only improves communication skills but also cultivates collaborative and self-directed learning methods. Moreover, tandem learning seems to be an optimized model for understanding mutual cultures in language education. Intercultural communication competence (ICC) is the ability to execute effective and appropriate communication behaviours that negotiate each other's cultural identity or identities in a culturally diverse environment (Chen \& Starosta, 1999 , p. 28). It is also suggested that effective ICC may include empathy, motivation, tolerance for uncertainty, respect, flexibility, self-knowledge, other types of knowledge and so forth (Byram, 1997; Alptekin, 2002; Kohn, 2013). Therefore, the tandem learning method can facilitate the acquisition of authentic language as well as intercultural competences since this pedagogical model is based on the mutual exchange between tandem partners who are familiar with their own cultures. However, it has not been estimated how much the tandem model can cultivate intercultural communication competence.

\section{Literature Review and Research Focus}

Most previous tandem studies have focused on e-tandem methods due to the lack of learning partners or foreign students during onsite/offline sessions (Kim \& Koh 2018) and have developed or designed curricula. St. John and Cash (1995), Little and Brammerts (1996), Woodin (1997), Shetzer (1997), Appel (1999), and Little et al. (1999) discussed the principles, methods, and effects of learning in tandem by e-mail. In research related to web-based tandem learning, Appel and Mullen (2000) improved the e-mail environment and conducted error analysis on vocabulary and grammar that appeared through the web to be specially designed to explore the development direction of tandem learning. Cziko (2004) proposed 
an easy way to learn a second language by developing the Electronic Network for Language and Culture Exchange (ENLACE) using communication media. Noccetti (2012) also introduced computer-based tandem learning as a method of teaching English to adult learners in Italy. Elia (2006) examined how to study English and Italian using Skype, which provides Voice over Internet Protocol (VoIP) services. Vassallo \& Telles (2006) discussed the principles and characteristics of online tandem programmes using Windows Live Messenger and discussed the possibility of introducing tele-tandem learning for all foreign language learning in Brazil.

Over the decades, although tandem learning has been researched in various fields, very limited research has been conducted in relation to Intercultural Communicative Competence (ICC). Other studies have linked the effects of tandem learning with the promotion of intercultural communication (Calvert, 1999; Schenker, 2012; Woodin, 2010). Based on an American-German telecollaboration, Schenker (2012) explored ICC within the framework of Byram's model (1997) and revealed that no significant change was found in cultural learning. Other studies, on the other hand, have demonstrated strong correlation between language learning and improving ICC in tandem learning by employing the method of conversational analysis (Woodin, 2013; Sabbah-Taylor, 2017).

The above studies have certainly examined the effectiveness of tandem learning in acquiring language skills through e-tandem programmes. However, it has not been properly shown that tandem learning will improve ICC. Hence, this study will try to assess ICC in onsite tandem classrooms. The following questions guided the study:

(1) Can tandem classrooms improve linguistic competence as well as intercultural communication competence?

(2) How effective are tandem classrooms in enhancing intercultural communicative competence?

\section{Research Context and Instrument}

In 2016, over the course of the second semester, a number of full-fledged tandem classrooms for paired languages, including Hindi-Korean, Japanese-Korean, Vietnamese-Korean, and Russian-Korean, were conducted at Busan University of Foreign Studies. Each onsite/offline tandem classroom consisted of 15-weeklong modules with a 3-hour weekly session. The basic purpose of these tandem classrooms was to build linguistic communication skills. However, the modules 
cover some specified themes, including cultural differences between the partners, to promote the understanding of each other's culture.

The participants in the study were 87 full-time undergraduate students enrolled in the university. The students were checked by completing a simple demographic profile before the survey was conducted by the school's Centre for Teaching and Learning.

In addition, an in-depth interview was also conducted with several students who participated in Polish-Korean and Thai-Korean tandem programs at Hankuk University of Foreign Studies in 2019.

Table 1. Participant demographics

\begin{tabular}{llrc}
\hline & \multicolumn{1}{c}{ Categories } & Student No. & Percentage (\%) \\
\hline \multirow{2}{*}{ Gender } & Male & 34 & $39.1 \%$ \\
\cline { 2 - 4 } & Female & 53 & $60.9 \%$ \\
\hline \multirow{2}{*}{ Grade } & First Year & 2 & $2.3 \%$ \\
\cline { 2 - 4 } & Second Year & 34 & $39.1 \%$ \\
\cline { 2 - 4 } & Third Year & 31 & $35.6 \%$ \\
\cline { 2 - 4 } & Fourth Year & 20 & $23.0 \%$ \\
\hline Total & & 87 & $100 \%$ \\
\hline
\end{tabular}

Source: Tandem Centre (Report on Tandem Effect: ACE 4-3-4).

This study used a survey on ICC developed by the Centre for Teaching and Learning (see Appendix). This questionnaire consists of items related to empathy, respect, tolerance, self-knowledge, other types of knowledge, and motivation. Ordinal responses were provided on a 5-point Likert scale, ranging from 1 (strongly disagree) to 5 (strongly agree).

Table 2. Descriptive statistical analysis

\begin{tabular}{lccccccc}
\hline & $\mathrm{N}$ & $\begin{array}{c}\text { Mini- } \\
\text { mum }\end{array}$ & $\begin{array}{c}\text { Maxi- } \\
\text { mum }\end{array}$ & $\mathrm{M}$ & SD & SKEW.P & KURT \\
\hline Gender & 87 & 1 & 2 & 1.61 & .491 & -.445 & -1.844 \\
\hline Grade & 87 & 1 & 4 & 2.78 & .836 & .089 & -.934 \\
\hline CA1 & 87 & 2 & 5 & 4.07 & .759 & -.280 & -.729 \\
\hline CA2 & 87 & 2 & 5 & 3.54 & .860 & .041 & -.613 \\
\hline CA3 & 87 & 3 & 5 & 4.68 & .581 & -1.649 & 1.737 \\
\hline CA4 & 87 & 1 & 5 & 3.90 & .977 & -.631 & .141 \\
\hline
\end{tabular}




\begin{tabular}{lccccccc}
\hline & N & $\begin{array}{c}\text { Mini- } \\
\text { mum }\end{array}$ & $\begin{array}{c}\text { Maxi- } \\
\text { mum }\end{array}$ & M & SD & SKEW.P & KURT \\
\hline CA5 & 86 & 2 & 5 & 4.12 & .773 & -.674 & .276 \\
\hline CA6 & 87 & 1 & 5 & 4.14 & .942 & -1.050 & .721 \\
\hline CA7 & 87 & 2 & 5 & 3.94 & .826 & -.145 & -.961 \\
\hline CA8 & 87 & 3 & 5 & 4.30 & .701 & -.491 & -.851 \\
\hline CA9 & 87 & 2 & 5 & 4.39 & .783 & -1.265 & 1.253 \\
\hline CA10 & 87 & 2 & 5 & 4.15 & .815 & -.548 & -.553 \\
\hline CA11 & 87 & 1 & 5 & 4.00 & .792 & -.718 & 1.257 \\
\hline CA12 & 87 & 1 & 5 & 4.21 & .878 & -1.054 & 1.058 \\
\hline CA13 & 87 & 1 & 5 & 3.75 & 1.070 & -.466 & -.544 \\
\hline CA14 & 87 & 1 & 5 & 4.10 & .876 & -.947 & .968 \\
\hline CA15 & 87 & 1 & 5 & 3.51 & 1.311 & -.568 & -.831 \\
\hline CA16 & 86 & 1 & 5 & 3.78 & 1.202 & -.934 & .132 \\
\hline CA17 & 87 & 1 & 5 & 4.03 & .970 & -1.244 & 1.762 \\
\hline CA18 & 87 & 1 & 5 & 4.10 & .977 & -1.284 & 1.812 \\
\hline
\end{tabular}

Source: Tandem Centre (Report on Tandem Effect: ACE 4-3-4).

\section{Research Results}

The framework survey was administered through the classrooms to measure the effectiveness of the tandem classrooms in relation to intercultural communicative competence and to explore how the students perceived their level of competence after completing the tandem classes.

As Table 3 indicates, no significant difference was found in the post-survey regardless of the question items. The overall perceptions of the students, regardless of gender and grade, were considerably different from the initial expectation that the onsite tandem learning method increases ICC. The result is highly likely to stem from discrepancy in goals (i.e. improving language skill vs. intercultural communicative competence) rather than variation in the instructional learning method (i.e. traditional learning vs. tandem learning). In other words, according to the students who participated in the tandem class at HUFS, they enrolled in the class to improve their language competence through teaching and learning with their partners based on the given curriculum, but not to understand each other's culture. 
Table 3. Pre-post survey analysis

\begin{tabular}{llllll}
\hline \multirow{2}{*}{ Difference } & M & N & SD & SE \\
\cline { 2 - 6 } & Post-survey & 4.0391 & 87 & .53406 & .05726 \\
\hline
\end{tabular}

Following the analysis of the overall perceptions, this study analysed the students' perceptions of the ICC items, as summarized in Table 4. No statistically meaningful level of significance was found for gender (male students: correlation .132 , p-value .457; female students: correlation .012, p-value .933). Unlike the initial expectation, tandem method did not greatly improve interaction. This may indicate that students experienced difficulties in discussing with their course participants and tandem partners.

Table 4. Analysis of the result

\begin{tabular}{|c|c|c|c|c|c|c|c|c|c|}
\hline & & \multicolumn{5}{|c|}{ Difference (Pre-Post) } & \multirow{3}{*}{$\mathrm{t}$} & \multirow{3}{*}{ df } & \multirow{3}{*}{ p-value } \\
\hline & & \multirow[t]{2}{*}{ M } & \multirow[t]{2}{*}{ SD } & \multirow[t]{2}{*}{ SE } & \multicolumn{2}{|c|}{$\begin{array}{c}95 \% \\
\text { Confidence } \\
\text { Interval }\end{array}$} & & & \\
\hline & & & & & lower & upper & & & \\
\hline $\begin{array}{l}\text { Differ- } \\
\text { ence }\end{array}$ & $\begin{array}{l}\text { Pre- } \\
\text { Post }\end{array}$ & -.01904 & .80847 & .08668 & -.19135 & .15326 & -.220 & 86 & .827 \\
\hline
\end{tabular}

Although the upper-grade students' ICC levels showed little difference, their perceptions did not display a significant result when examined by t-test. This result does not attest to the existence of an interaction effect between instructional method and grade group. It is also notable that some of the upper-grade students were not able to understand each other's culture because of their limited languages skills.

Table 5. Analysis: upper-grade students

\begin{tabular}{|c|c|c|c|c|c|c|c|c|c|}
\hline & & \multicolumn{5}{|c|}{ Difference (Pre-Post) } & \multirow{3}{*}{$\mathrm{t}$} & \multirow{3}{*}{ df } & \multirow{3}{*}{ p-value } \\
\hline & & \multirow[t]{2}{*}{$\mathbf{M}$} & \multirow[t]{2}{*}{ SD } & \multirow[t]{2}{*}{ SE } & \multicolumn{2}{|c|}{$\begin{array}{c}95 \% \\
\text { Confidence } \\
\text { Interval }\end{array}$} & & & \\
\hline & & & & & lower & upper & & & \\
\hline $\begin{array}{l}\text { Dif- } \\
\text { fer- } \\
\text { ence }\end{array}$ & $\begin{array}{l}\text { Pre- } \\
\text { Post }\end{array}$ & .01961 & .80591 & .11285 & -.20706 & .24627 & .174 & 50 & .863 \\
\hline
\end{tabular}




\section{Conclusion}

The aim of this study was to assess intercultural communication competence in onsite tandem learning. Over the years, only a small number of studies have examined the impact of tandem classrooms on intercultural communicative competence. Based on the current study of 87 students implemented in full-fledged tandem classrooms, the results indicate that participating in tandem classrooms does not significantly cultivate the intercultural communication competence of the students. There is no doubt that tandem learning increases one's language capacity. However, the hypothesis that tandem communication will also improve one's intercultural communication competence has not been proven in this study. Additional interviews with students who also participated in the tandem program at Hankuk University of Foreign Studies were conducted to find out why the hypothesis was not valid. The reason for this outcome is that tandem classrooms are primarily designed to strengthen students' language communication competence, not to foster their intercultural communication skills. It should be noted that intercultural communication competence may vary depending on the level of language proficiency of students, and there could be a limitation of the students' verbal expressions regarding understanding the other culture. In other words, the existing curriculum may not be adequate for cultivating two competences simultaneously. Therefore, the cultivation of intercultural communication competence in the tandem programme can only be achieved by the development of an appropriate curriculum and pedagogy that considers the linguistic level of the participants. The results of this study, with no significant statistical data for the development of ICC, thus demonstrate the necessity of the improvement of future tandem programmes.

\section{Research limitations}

It may be difficult to assess intercultural communicative competence. No suitable instruments have yet been developed to measure this competence. In this paper, a self-developed tool was employed, although this tool still leaves many aspects to be desired. Moreover, cultural differences or national characteristics were not used to examine intercultural communicative competence in this research. 


\section{Acknowledgements}

This work was supported by Hankuk University of Foreign Studies Research Fund of 2020. It is also noted that this paper was based on the unpublished Tandem Report (ACE 4-3-4) conducted by Tandem Centre.

\section{References}

Alptekin, C. (2002). Towards intercultural communicative competence in ELT. ELT Journal 56(1), 57-64.

Appel, C. (1999). Tandem language learning by e-mail: some basic principles and a case study. CLCS Occasional Paper No. 54, Dublin: Trinity College.

Appel, M.C. \& Mullen T. (2000). Pedagogical considerations for a web-based tandem language learning environment. Computers \& Education 34, 291-308.

Brammerts, H. (2001). Autonomes Sprachenlernen im Tandem: Entwicklung eines Konzepts (Autonomous Language Learning in Tandem: Development of a concept). In Selbstgesteuertes Sprachenlernen im Tandem: Ein Handbuch (Self-controlled Language Learning in Tandem: A Manual), H. Brammerts, and K. Kleppin (eds.), 9-16. Tübingen: StauffenburgBrammerts.

Byram, M. (1997). Teaching and Assessing Intercultural Communicative Competence. Bristol: Multilingual Matters.

Tandem Centre (2017). Report on Tandem Effect (ACE 4-3-4). Unpublished Report. Busan University of Foreign Studies.

Calvert, M. (1992). Working in tandem: peddling an old idea. Language Learning Journal, 6, 17-19.

Calvert, M. (1999). Tandem: A vehicle for language and intercultural learning. The Language Learning Journal, 19(1), 56-60. doi:10.1080/09571739985200111

Chen, G. M. \& Starosta, W. J. (1999). A review of the concept of intercultural awareness. Human Communication, 2, 27-54.

Cziko, G.A. (2004). Electronic tandem language learning (eTandem): A third approach to second language learning for the $21^{\text {st }}$ century. CALICO Journal 22(1), 25-39.

Elia, A., (2006). Language learning in tandem via skype, The Reading Matrix, 6, 269-280.

Kim, D. \& Koh, T. (2018). Tandem translation classroom: a case study. Journal of Multilingual and Multicultural Development, 39, 97-110.

Kohn, K. (2013, March). Intercultural communicative competence: an English as a lingua franca perspective. Paper presented at TESOL Arabia, Dubai, UAE.

Little, D., \& Brammerts, H. (1996). A guide to language learning in tandem via the Internet. CLCS Occasional Paper, No. 46, Dublin: Trinity College.

Little, D., et al. (1999). Evaluating tandem language learning by e-mail. Report on a bilateral project. CLCS Occasional Paper, No. 55, Dublin: Trinity College.

Noccetti, S. (2012). Learning L2 English in Tandem Partnerships On-Line. Sino-US English Teaching, 9(7), 1318-1324. 
Rosanelli, M. (1992). Language in Tandem: Autonomy and Language Acquisition. Merano: Alpha and Beta Verlag.

Sabbah-Taylor, A. (2017). Interactional and intercultural competence in tandem learning: A micro-analytic perspective, Unpublished Ph.D. thesis, Newcastle University.

Saeideh, A. \& Zamanian, J. (2014). Intercultural Communicative Competence in Foreign Language Classroom. International Journal of Academic Research in Business and Social Sciences, 4(11), 9-16.

Schenker, T. (2012). Intercultural Competence and Cultural Learning through Telecollaboration. CALICO Journal, 29(3), 449-470.

Woodin, J. (2013). Native of Intercultural Speakers? An Examination of Dyadic Conversations between Spanish- and English- Speaking Tandem Learners. In Language and intercultural communication in the new era, Sharifian, F., \& Jamarani, M. (eds.). New York: Routledge.

Shetzer, H.S. (1997). Critical reflection on the use of e-mail in teaching English as a second language, Unpublished Master thesis, University of Illinois.

St John, E., \& Cash, D. (1995). German language learning via e-mail: a case study. ReCALL, $7(2), 47-51$.

Tardieu, C., \& Horgues, C. (eds.). (2020). Redefining Tandem Language and Culture Learning in Higher Education. New York: Routledge.

Woodin, J. (1997). E-mail tandem learning and the communicative curriculum. ReCALL, 9(1), 22-33.

Woodin, J. (2010). Cultural categorisation: what can we learn from practice? An example from tandem learning, Language and Inter-cultural Communication, 10(3), 225-242.

Vasallo, M.L., \& Telles, J.A. (2006). Foreign language learning in Tandem. Theoretical Principles and Research Perspectives. The ESPecialist 25(1), 1-37.

\section{Appendix.}

Intercultural Communicative Competence Instrument (Survey)

The following statements and questions are related to how you perceive your global cultural competency through the tandem classroom.

Please indicate your agreement or disagreement with each statement based on the following Likert scale:

(5) = strongly agree (4) = somewhat agree (3) = neutral (2) = somewhat disagree (1) = strongly disagree

CA1. I am interested in the history and culture of other countries.

CA2. I am aware of the differences or similarities of other religious or cultural practices. 
CA3. I think we should not discriminate against another person due to their different nationality or gender.

CA4. I think multiculturalism enriches our lives and society.

CA5. I think ethics and morality can be changed according to the specificity of the age, country, and historical situation.

CA6. I like to eat foreign food.

CA7. I fully accommodate the lifestyles of other countries, although they are not familiar to me.

CA8. I like to be exposed to various cultures and languages.

CA9. I want to be friendly with foreign students, and it would be good to work together as a team.

CA10. Even if I go to other countries, I am confident that I will do well.

CA11. I have my own norms, but I flexibly act according to the circumstances rather than stick to my norms.

CA12. I will not miss the opportunity to challenge myself no matter how hard it is.

CA13. I am not greatly stressed even if my living environment changes.

CA14. I consider the global stage as an opportunity rather than a threat so that I challenge myself positively.

CA15. I have participated in various cultural exchange programmes and events.

CA16. I have travelled/studied abroad.

CA17. I contact my foreign friends via SNS or e-mail.

CA18. I have taken a course related to foreign culture. 